\title{
Field-Circuit Coupled Analysis of an In-Wheel Switched Reluctance Motor with Outer Rotor for EV Applications
}

\author{
Yiduan Chen ${ }^{1, a}$, Huijuan Liu ${ }^{1, b}$, Xiang Zhao ${ }^{1}$, \\ Haijiao Zhang ${ }^{1}$, Zhongfeng Zuo ${ }^{1}$ \\ ${ }^{1}$ School of Electrical Engineering, Beijing Jiaotong University, Beijing, 100044, China \\ a12125836@bjtu.edu.cn, bjjliu@bjtu.edu.cn
}

Keywords: In-wheel motor, switched reluctance motor (SRM), field-circuit coupled method, angle position control (APC)

\begin{abstract}
Switched reluctance motor (SRM) is potential to be applied in electric vehicle as an in-wheel drive motor because of its unique feature, such as being allowed to operate in a wide speed range with high efficiency. In this paper, a field-circuit coupled dynamic model is developed with 2D finite element method in Maxwell being proposed to compute the performances of a $10 \mathrm{~kW} / 800 \mathrm{rpm}$ SRM using the angle position control (APC) strategy. The nonlinear magnetization characteristics have been considered and calculated by FEA. The magnetic fields, windings current, the electromagnetic torque and the terminal characteristics of the prototype SRM are investigated.
\end{abstract}

\section{Introduction}

In-wheel motors for electric vehicle (EV) application is a hot topic among researchers due to environmental concerns[1]. It greatly simplify the mechanical part of the electric vehicle. In last decades, both radial and axial flux permanent magnet (PM) motors are widely used in most of the in-wheel applications [2,3,4]. PM motors offer the highest torque density and therefore will potentially have the lowest weight for given torque and power rating. However, fixed flux magnets limit the speed range of the motor, and there are the dangers of demagnetization phenomenon in permanent magnets. The induction and switched reluctance motors, which have similar torque density, have also been used as in-wheel drive motors [5,6].

Comparing with other motors, SRM is potential to apply in EV applications on account of its simple and reliable structure. SRM enjoys flexible control, high efficiency in a wide range of speed, and easy implementation of four-quadrant operation, which is much more important for improvement of electric vehicle performance [7].

However, due to the double salient structure of the SRM, the non sinusoidal currents and the magnetic saturation in the motor core during motor operation, the simple and unified mathematical model and analytical equation can not be get easily [8]. The finite element method is a kind of discrete mathematics method which is based on the magnetic field analysis, the SRM model can be precisely built by the method, the SRM performance can be comprehensively and systematically analyzed [9].

In this paper, a new field-circuit coupled finite element method by using Maxwell is developed to simulate a 3-phase, 12/8 pole, 10kW/800rpm SRM and its control system. The magnetic fields distribution, the torque, the currents of the SRM with outer rotor are presented.

\section{The In-wheel SRM Model}

The model's main dimensions are determined with the design specifications listed in Table 1.

\begin{tabular}{cccc} 
& Table 1 & Main Dimensions & \\
\hline \hline Rated Power $(\mathrm{kW})$ & 10 & Rated Speed (rpm) & 800 \\
Rated Voltage $(\mathrm{V})$ & 282 & Shaft Length (mm) & 150 \\
Stator pole number & 12 -pole & Rotor Pole number & 8 -pole \\
Stator OD $(\mathrm{mm})$ & 95 & Rotor OD $(\mathrm{mm})$ & 154 \\
\hline
\end{tabular}




\begin{tabular}{cccc}
\hline Stator ID $(\mathrm{mm})$ & 30 & Rotor ID (mm) & 95.5 \\
Stator yoke thickness $(\mathrm{mm})$ & 20 & Rotor yoke thickness (mm) & 12 \\
Stator pole arc (degree) & 15 & Rotor pole arc (degree) & 16 \\
\hline
\end{tabular}

The two-dimensional finite element model was created through finite element analysis software Maxwell 2D, and a cross section is shown in Figure 1. To achieve a maximum flux of phase windings, the coils should be anti-series connected and an almost linear phase flux waveform can be obtained. As the finite element model of SRM was built, the dynamic simulation could be operated by the transient module of MAXWELL 2D.

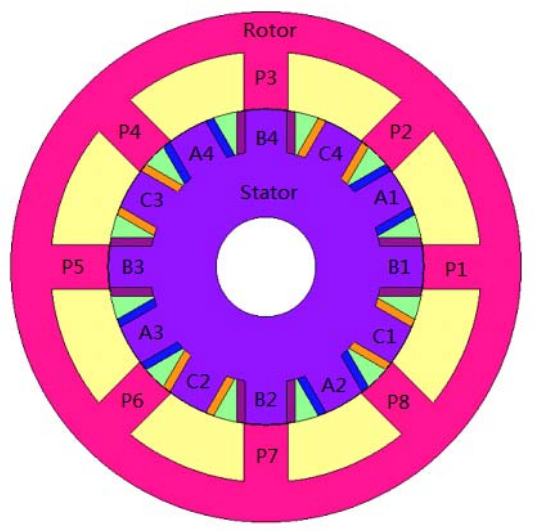

Fig. 1. The 2D geometric model for in-wheel SRM

\section{The Control Strategy of SRM}

The external circuit is composed of power converter model and the driver circuit (shown in Fig. 2). The on/off of the main switched tube is depended on position signal of the rotor, so the rotor position $\mathrm{P}$ is a variable, the commutation signal for power converter is provided by rotor position $\mathrm{P}$. In a power converter, the each phase equivalent winding is composed of the coil LA-LC of a SRM, coil resistance of RA-RC and the leakage inductance of the ends (LAend, LBend and LCend) series together, S_1-S_6 are served as the main switches. In the drive circuit, VSA, VSB and VSC are served as the controlled voltage sources, according to the rotor position, which generate pulse voltage signal to control voltage switches $\mathrm{S}_{-} 1-\mathrm{S} \_6$, then each phase winding is alternately electrified[10].
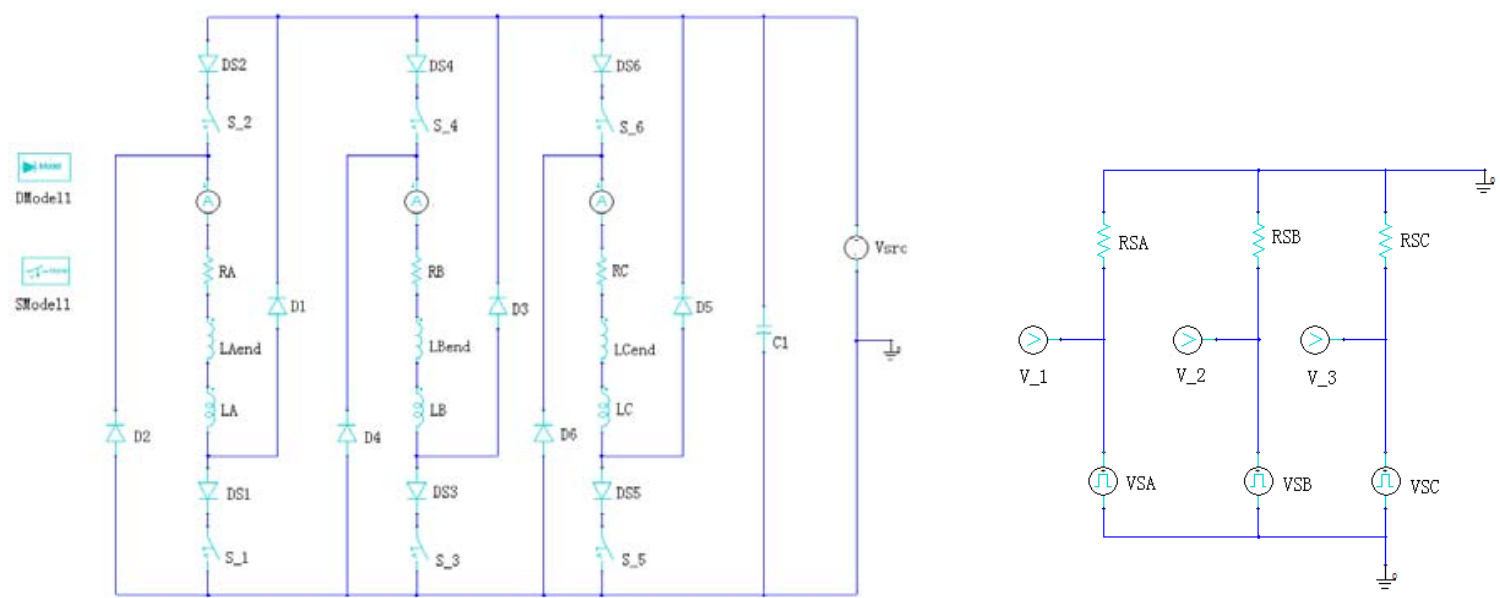

Fig. 2. The power converter model and the drive circuit for in-wheel SRM

As we can know, field-circuit coupled method puts the terminal voltage of the motor as the known quantity, combines the finite element equations of the electromagnetic field with the winding circuit equations through the electromotive force (EMF) of stator windings and solves the magnetic vector potential and the current in the windings directly, which omits the current iterative in the process of the finite element analysis and improves the calculation accuracy of 2D electromagnetic field greatly by considering the motor end effect at the same time. So we use it to the study.

The system of external circuits and models defined by ANSOFT software can be simulated. 


\section{Simulation Results and Analysis}

The simulation parameters of the finite element are adopted as following, power supply is DC-282V, the cycle of switch conduction is $45^{\circ}$, so a phase conduction intervals is $15^{\circ}$. When angle position control is used, the given speed is 900rpm.

In this study, the angle position control method is used to adjust the value of output torque and reduce the ripple of the torque by changing the turn-on and turn-off angles. We arrange the simulation data that the maximum, the minimum and the average values of the torque $\left(T_{\max }, T_{\min }\right.$ and $\mathrm{T}_{\mathrm{av}}$ ) under different initial position angels in the Table 2 and different conduction angels in the Table 3.

\begin{tabular}{ccccc} 
Table 2 & \multicolumn{5}{c}{ Torque Data of Different Initial Position Angles } \\
\hline \hline $\begin{array}{c}\text { Initial } \\
\text { position } \\
\text { angle }(\mathrm{deg})\end{array}$ & $\begin{array}{c}\text { conducti } \\
\text { on angle } \\
(\mathrm{deg})\end{array}$ & $\begin{array}{c}\mathrm{T}_{\max } \\
(\mathrm{N} \cdot \mathrm{m})\end{array}$ & $\begin{array}{c}\mathrm{T}_{\min } \\
(\mathrm{N} \cdot \mathrm{m})\end{array}$ & $\begin{array}{c}\mathrm{T}_{\mathrm{av}} \\
(\mathrm{N} \cdot \mathrm{m})\end{array}$ \\
7.5 & 14.5 & 108 & 16 & 62 \\
5 & 14.5 & 152 & 16 & 84 \\
7.5 & 14.5 & 180 & 10 & 95 \\
\hline
\end{tabular}

From the Table 2, we can find that conducting the main switches ahead can ensure the output of the motor and get the required torque and power, but, if the initial position angle is too small, the effect will be little and making new problems. So during the simulations as following we set the initial position angle to $7.5 \mathrm{deg}$ to make the center line of the stator tooth wound by coil A1 being aligned with the center line of the rotor slot between the two poles P1 and P2.

\begin{tabular}{ccccc} 
Table 3 & \multicolumn{5}{c}{ Torque Data of Different Conduction Angles } \\
\hline \hline $\begin{array}{c}\text { Initial } \\
\text { position } \\
\text { angle }(\mathrm{deg})\end{array}$ & $\begin{array}{c}\text { conducti } \\
\text { on angle } \\
(\mathrm{deg})\end{array}$ & $\begin{array}{c}\mathrm{T}_{\max } \\
(\mathrm{N} \cdot \mathrm{m})\end{array}$ & $\begin{array}{c}\mathrm{T}_{\min } \\
(\mathrm{N} \cdot \mathrm{m})\end{array}$ & $\begin{array}{c}\mathrm{T}_{\mathrm{av}} \\
(\mathrm{N} \cdot \mathrm{m})\end{array}$ \\
7.5 & 12 & 152 & 4 & 78 \\
7.5 & 14.5 & 152 & 16 & 84 \\
7.5 & 19.5 & 154 & 98 & 126 \\
7.5 & 22.5 & 148 & 92 & 120 \\
\hline
\end{tabular}

From the Table 3, we can find that when the time of power supply increases, the width of the current waveform will increase. Along with the $\theta_{\text {off }}$ moving backward, the output torque ripple will be smaller obviously. But the turn-off angle should not be too large.Because the torque waveform becomes worse without ripples reducing.
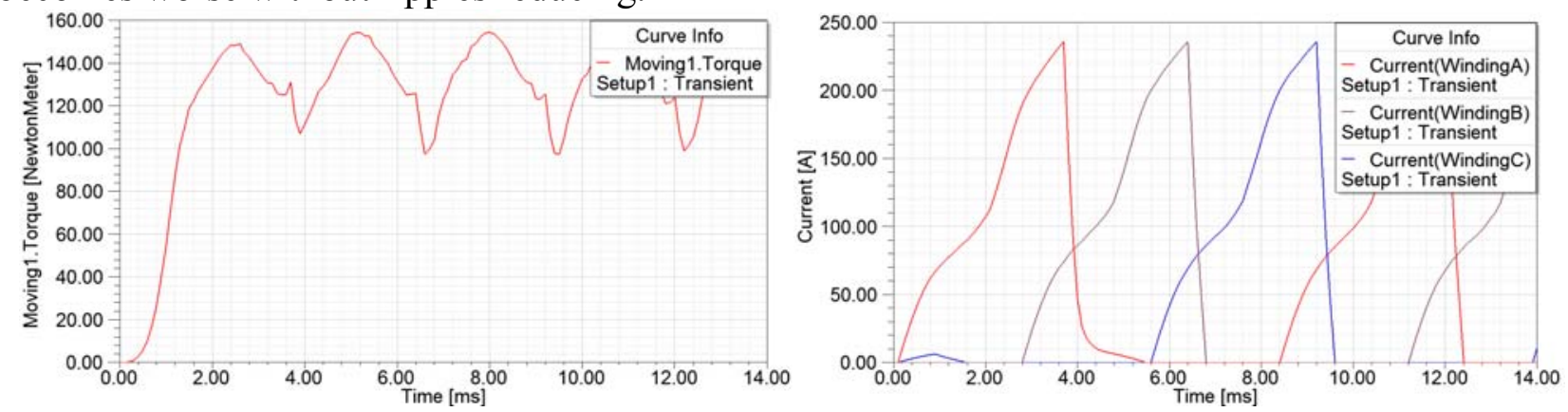

Fig. 4. The torque and currents waveform when the initial position angle is $7.5 \mathrm{deg}$ and the conduction angle is $19.5 \mathrm{deg}$

The turn-on angle $\theta_{\text {on }}$ of the main switch devices has very obviously effect on the control of the current size. Conduct the switches ahead, namely, reduce $\theta_{\text {on }}$ to increase the time when the current rises linearly, then the peak current and the width of the current waveform will increase so that the motor output torque and power will improve. But the output power will increase little when the $\theta_{\text {on }}$ is too small, and it will reduce the efficiency.

\section{Summary}

This paper focuses on the performance simulation of a in-wheel SRM (10kW/800rpm) for EV 
applications. All studies show that we can adjust the turn-on angle $\theta_{\text {on }}$ and the turn-off angle $\theta_{\text {off }}$ to change the current peak value and rms value, then produce the desired torque. The conclusions can be obtained as follows:

(1) In order to ensure the output of the motor, the switches should be conducted ahead, namely, reduce the $\theta_{\text {on }}$ to improve the motor output torque and output power. But the output power of the motor will increase little when the $\theta_{\text {on }}$ is too small and it will reduce the efficiency, bring on the vibration and noise; and the operation stability of the motor will be worse correspondingly.

(2) The $\theta_{\text {off }}$ has effect on the waveform of the phase current. Along with the $\theta_{\text {off }}$ moving backward, the output torque ripple will be smaller obviously. It also can regulate the current size and shape by adjusting the $\theta_{\text {off }}$.

\section{References}

[1] R. Madhavan, B. G. Fernandes, "A Novel Axial Flux Segmented SRM for Electric Vehicle Application," IEEE Electrical Machines(ICEM), Sept. 2010. pp. 1-6.

[2] F. Caricchi, T. Crescimbini, F. Mezzetti and E. Santini, "Multistage Axial-Flux PM Machine for Wheel Direct Drive," IEEE Trans. On Ind. Appl., vol.32, no.4, pp.882-888,1996.

[3] M. Terashima, T. Ashikaga, T.Mizuno, K. Natori, N. Fujiwara and M. Yada, "Novel Motors and Controllers for High-Performance Electric Vehicle with Four In-Wheel Motors," IEEE Trans. On Ind. Elec., vol.44, no.1, pp.28-38,1997.

[4] F. Protumo, Z. Zhang and A. Tenconi, "Axial Flux Machines Drives: A New Viable Solution for Electric Cars," IEEE Trans. On Ind. Elec., vol.44, no.1, pp.39-45,1997.

[5] M.C. Tsai, C.C. Muang and Z.Y. Huang, "A New Two-Phase Homopolar Switched Reluctance Motor for Electric Vehicle Applications," in Magnetism and Magnetic Materials, vol. 267, pp. 173-181, Elsevier, 2003.

[6] A. Benoudjit, A. Guettafi and N. Nait Said, "Axial Flux Induction Motor for On-Wheel Drive Propulsion System," in Electric Machines and Power Systems, vol.28, pp. 1107-1125, Taylor\&Francis, 2000.

[7] Wang Yaling, Xu Yanliang, Wang Yufang and Zhang Yun, "Outer-Rotor Switched Reluctance Motor and its Control System Used in Electric Vehicles," IEEE Electrical Machines and Systems(ICEMS), Aug. 2011, pp. 1-4.

[8] Wang Honghua. Switched Reluctance Motor Speed Control Technology [M]. Beijing: Mechanical Industry Press, 1999.

[9] H.Le-Huy, P. Brunelle, Design and Implementation of a Switched Reluctance Motor Generic Model for Simulink SimPowerSystems, Electrimacs 2005 Conference.

[10]Zhou Hui-Jun, Ding, Zhen-Min Yu. Maxwell 2D Based on the Switched Reluctance Motor Simulation [J]. Micro motor. 2007, 7:10 12.

[11]Ling Yuelun, Wang Mianhua, Wang Yan and Wang Fenli, "Simulation Research on Switched Reluctance Motor Modeling and Control Strategy based on ANSOFT," IEEE Measuring Technology and Mechatronics Automation (ICMTMA), 2010, pp.374-377.

[12]M. A. Cinar, F. E. Kuyumcu, "Design and Drive Simulation of an In-Wheel Switched Reluctance Motor for Electric Vehicle Applications," IEEE Electric Machines \& Drives Conference(IEMDC), May 2007, PP. 50-54. 